\title{
Breve historia de la Bordetella pertussis, una elusiva damisela
}

\author{
WALTER LEDERMANN D.
}

\section{Brief history about Bordetella pertussis, an elusive mademoiselle}

\begin{abstract}
El sistema natural de las enfermedades infecciosas es idéntico al sistema natural de los microorganismos que las producen.
\end{abstract}

\section{Ferdinand Klebs}

Las palabras de Klebs ${ }^{1}$ describen muy bien el enigma de la coqueluche, misteriosa enfermedad asociada a una elusiva bacteria. Ahora que ésta es conocida, todos los microbiólogos la buscan, aunque sin mucho éxito. Una bacteria fastidiosa al momento de aislarla, es increíblemente bella cuando brilla, como una perla, en al agar carbón, o se la divisa, envuelta en un halo dorado, en la oscuridad del microscopio de fluorescencia.

Hasta el advenimiento del siglo XX se creía fuertemente que el causante de la tos ferina era un hongo. En 1870 Letzerich describió la existencia de hongos en los niños que tosían en quintas con reprise, unos esporos pequeños, redondeados o elípticos, de color pardo rojizo, que germinaban parcialmente para formar filamentos. En su auxilio vino Tschamer, quien los cultivó y los inoculó en conejos, describiendo un micelio filamentoso, como una zooglea, que denominó Ustilago maidis var Capnodium citri $^{2}$. Aunque en 1883 serían rebatidos por Burger, quien publicó el hallazgo en la expectoración de los coqueluchosos de un bacilo pequeño y elipsoidal, que pudiera, con harta imaginación, corresponder a la Bordetella que hoy conocemos, la creencia en la etiología fúngica de la coqueluche persistiría hasta el aislamiento triunfal del patógeno por Bordet y Gengou en 1906. "La pululación -dicen Bordet y Gengou al describir su hallazgo- era de una abundancia tal y de una pureza tan perfecta, que era imposible rehusarse a admitir una relación de causalidad directa entre esta infección y la aparición de la coqueluche. Pero el microbio se mostró rebelde a todas las tentativas que se hicieron para cultivarlo". "Hasta que nosotros lo intentamos", les faltó agregar.
Bordet y Gengou tuvieron precursores, aparte del mencionado Burger. En 1887 Afanassjew describió en forma bastante acertada al bacilo, pero no pudo cultivarlo, tarea en la que también fracasaron Czaplewski y Hensel. Diez años después, Koplik (sí, el mismo de las manchitas que anuncian el sarampión) cultivó en agar ascitis colonias perladas de Bacillus pertussis: sus detractores dicen que eran cultivos impuros, mezclados con Bacillus influenzae. Por la misma época, Spengler cultivó una bacteria parecida. Llegó el 1900 y no se acabó el mundo, como pronosticaban los augures iluminados, y en 1901 Jochmann y Krause aislaron en agar sangre, del esputo de un pequeño paciente, un bacilillo que llamaron Bacillus pertussis Eppendorf, honrando el sector de Hamburgo donde estaba situado su hospital. El nombre persistió, pero otra vez dijeron sus rivales que el cultivo era más influenzae que pertussis ${ }^{4}$. Viejas y olvidadas rencillas germánicas, que se reproducen incesantemente entre los científicos de todas las épocas y razas.

No sólo fue mérito de los franceses haber diseñado el famoso agar sangre-papa-glicerol que lleva su nombre, pues también lograron relacionar la sintomatología de la enfermedad con presencia del bacilo, que conservó el nombre de los germanos (pero sin el Eppendorf), demostrando que era el agente etiológico de la coqueluche. No obstante, el decenio que siguió al descubrimiento estuvo pleno de discusiones, culminando con los trabajos de Chievitz y Meyer en 1915, quienes concluyeron que "Bordet et Gengou avaient eu raison en désignant comme bacille de la coqueluche la germe décrit para eux" . Es interesante revisar la positividad de los cultivos del Bacillus pertussis, tomados de casos clínicos típicos, que obtuvieron diversos autores en busca de la confirmación de su participación etiológica (Tabla 1), rendimiento que no superan los cultivos actuales en el medio de Regan-Lowe.

Mas, antes de seguir, detengámonos un momento en las figuras de estos dos investigadores, cole- 
Tabla 1. Positividad de los cultivos de Bacillus pertussis (1906-1915)

\begin{tabular}{lcc}
\hline Autores & $\begin{array}{c}\mathbf{N}^{\mathbf{0}} \text { de cultivos } \\
\text { tomados }\end{array}$ & $\begin{array}{c}\mathbf{N}^{\mathbf{o}} \text { de cultivos } \\
\text { positivos }\end{array}$ \\
\hline Seiffert & 16 & 12 \\
Klimenko & 5 & 5 \\
Inaba y Finizio & 93 & 81 \\
Frankel & 38 & 8 \\
Arnheim & 20 & 6 \\
Odaira & 35 & 6 \\
Wollstein & 20 & 5 \\
Povitzky & 55 & 18 \\
Williams & 187 & 27 \\
Meyer y Chievitz & 101 & 37 \\
\hline
\end{tabular}

gas y amigos de habla gala, Bordet y Gengou, cuyos nombres quedaron indisolublemente unidos en la literatura médica por el bacilo de la coqueluche, así como por su medio de cultivo y por la célebre reacción de fijación del complemento. La fama, empero, trató a ambos en forma muy distinta, y la parte del león y el premio Nobel fueron a las manos de Jules Jean Baptiste Vincent Bordet, mientras Octave Gengou quedó como co-worker. Bordet era belga, cinco años mayor que Gengou, serio, metódico y genial; el francés, un bonhomme d'esprit, que se tomaba las cosas con más calma.

Jules Jean Baptiste Vincent nació en Soignies el 13 de junio de 1870 . Fue un niño precoz, brillante y vertiginoso, de manera que a los 22 años se había ya titulado de médico en la Universidad de Bruselas. ¿Dónde marcaba sus hitos la investigación médica y radicaba el centro de atracción para los jóvenes ansiosos de grandes descubrimientos? En el Instituto Pasteur, en París, y allá marchó Jules Jeann et al. Permaneció allí hasta 1901, cuando se le encomendó la creación y dirección de la filial belga en Bruselas, labor que cumplió hasta 1940. Se llevó, claro, a su ayudante tan simpático e inteligente, el joven Octave, y se pusieron de cabeza a estudiar en el fascinante campo de la inmunidad $\mathrm{y}$, de paso, encontrar el misterioso agente de la coqueluche.

- La alexina del suero, Octavio, es lo que permite al hombre matar a las bacterias invasoras: et c'est tout.

- Mais...

- ¿Mais quoi ?

- Ce n'est pas tout, mon cher maître, pues después de la inmunización aparece el otro componente de la inmunidad

De la discusión sale la luz, y de estos dos hombres encontrados salió el reconocimiento de los anticuerpos bactericidas generados por la vacunación, la utilísima reacción de fijación del complemento $\mathrm{y}$, como un experimento accesorio, el famoso medio de cultivo que posibilitaría el descubrimiento de la Bordetella. Fue un éxito adicional, pues el Premio Nobel le llegaría a Jules Jean en 1919 "por sus logros en el campo de la inmunología”. Después de los trabajos en la vacuna pertussis, el belga y el francés siguieron caminos distintos. Bordet descubrió el bacilo de la difteria aviaria, para sumirse luego en estudios de la coagulación y de las reacciones anafilácticas. La sombra de Gengou se esfuma, para reaparecer más tarde adhiriendo a las campañas humanitarias de Bordet. ¡Ah, sí, olvidaba que Jules Jean no sólo era un científico, sino también un hombre "humano"! En 1924 se unió a un grupo de científicos, quienes, espantados por las secuelas de los soldados gaseados en la Primera Guerra Mundial, redactaron un manifiesto a la Liga de las Naciones advirtiendo sobre el peligro de usar gases tóxicos en futuras guerras y, en 1958, adhirió a la petición de Linus Pauling para suspender los ensayos con bombas nucleares. Esta fue una petición controversial, pero Pauling logró la firma de 36 Premio Nobel, entre ellos Bordet, y de otros 9.000 científicos, Gengou incluido. Por cierto que la propuesta no fue acogida, pues siempre pesan más los hombres que matan que los que salvan vidas: prueba de ello es que en mi Enciclopedia Colliers, en la letra G, después de Gengis Khan no figura, por supuesto, Gengou Octave. Bordet publicó muchísimo, siendo su obra capital el Tratado de la Inmunidad en las Enfermedades Infecciosas. Murió en Bruselas el 6 de abril de 1961, próximo a cumplir 91 años, cuando Gengou llevaba ya cinco bajo tierra ${ }^{6}$.

Volvamos a la coqueluche. Esta enfermedad, la única de las pestes de la infancia que sobrevive inmutable al avance de la ciencia médica, era conocida desde mucho antes que naciera la preocupación por su agente causal. La primera descripción exacta de la tos ferina -la tos de las fieras... (¿acaso tosen así los leones?)- corresponde a Leo Schenk y Roger Baillon en el siglo XVI. Willis, Sydenham y Ettmüller la complementaron en el siglo XVII. En el siglo XVIII se describen grandes epidemias en toda Europa, motivando numerosos estudios, apreciados hoy más por pintorescos que por útiles. Hirsch declaraba en el siglo XIX que casi todos los países de la tierra han tenido epidemias y, de Europa, sólo es rara en las Islas Feroe y en Islandia ${ }^{2}$.

Grandes dudas y estériles discusiones ha suscitado siempre el nombre de la enfermedad. Los norteamericanos, de quienes somos, en medicina, una aplicada colonia científica, han adoptado el término latino per (intensa) tussis (tos); los españoles, ancestros cuyo idioma destruimos día a día, han preferido la pintoresca denominación de tos ferina, de la cual ya me he burlado más arriba; los franceses utilizan la enigmática coqueluche, cuyo origen se pierde en la noche de los tiempos.

¿De dónde viene "coqueluche"? Existen dos teorías principales sobre su origen. La más socorrida es onomatopéyica y dice que el término viene de coq, el "gallito" que culmina las quintas de tos. Coq, define mi Larousse, es el mâle de la poule, en tanto que coquelicot c'est une fleur, la amapola, y la menciono porque también se ha dicho que, habiendo sido empleada la tintura del opio, extraída de la amapola, para detener las crisis de tos, sería coquelicot el 


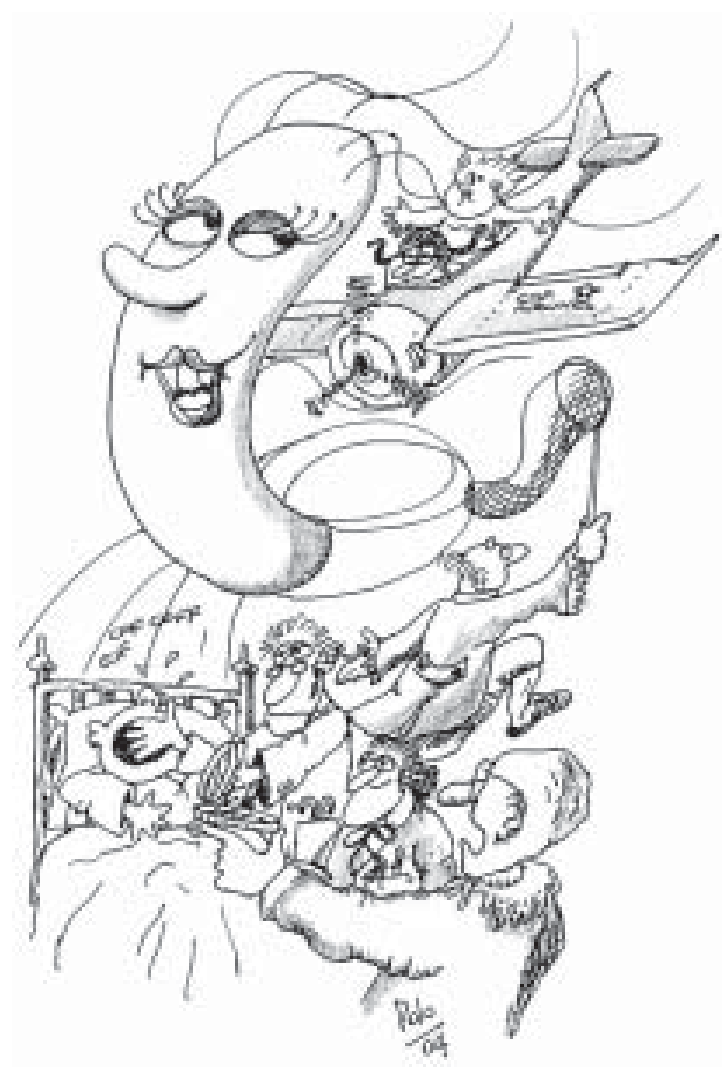

origen de coqueluche. La otra teoría aceptada hace devenir coqueluche de coqueluchon (lat. Cucullio), término que habría designado una caperuza aislante que se ponía a los niños tosedores o, quizás, a la que usaban los primitivos infectólogos. Mais, en francés caperuza y capuchón se traducen más bien como capuchon. Coque es la cáscara de frutas o de huevo, o el casco de un navío; coquille se refiere a lo mismo, pero más a la concha de los moluscos7. "En Picardía, dice en 1865 el profesor Trousseau, durante su clase magistral en el Hotel-Dieu de París, se la llamaba y se la llama todavía la toux qui houpe de donde los ingleses han sacado la whooping cough" . Y de donde, en consecuencia y literalmente, los españoles hubieran debido sacar la "hip hip tos", digo yo. Personalmente, pienso que coqueluche viene de coquette, es decir, la coqueta Bordetella, que se muestra en la inmunofluorescencia, pero no se deja capturar en el cultivo, nos elude y se burla de los microbiólogos.

Después de Bordet y Gengou, que posibilitaron el cultivo con el desarrollo de su célebre medio, conviene destacar a los más olvidados Auguste Hypolite Meyer e Yves Chievitz, que en 1916 publicaron el método de toma de muestra mediante "la placa de tos", complementado luego por Mauritzen. Meyer y Chievitz no hacían toser al niño sobre la placa de tos: usaban una pequeña espátula, en la cual recogían la expectoración filante al momento de la quinta, para diluirla luego en solución salina estéril y sembrarla "con la placa de cultivo a la cabecera del enfermo". Mauritzen, hombre práctico, observó que bastaba meter el bajalenguas para ganarse la hostilidad del enfermito, cosa que sabemos todos los pediatras, y prefirió ponerle la placa de Petri frente a la boca al momento de toser, para recoger las gotitas de Pflügge. "La placa, precisa Julien Marie en 1935, debe abrirse al final del acceso de tos, de tal manera que la superficie del medio de cultivo quede a $10 \mathrm{~cm}$ de la boca del enfant, por alrededor de un cuarto de minuto: cet ensemencement constitue, d'après notre expérience, une manoeuvre capitale et délicate, et c'est d'elle que dépend la réussite de la culture. Nosotros, prosigue el profesor Marie, creemos que deben sembrarse al menos tres placas; estimando que el niño no puede toser a una orden nuestra ni menos metiéndole una cucharilla en la garganta, y no pudiendo permanecer a la espera de que tosa espontáneamente, aconsejamos explicar a una persona del ambiente, habitualmente la madre, la técnica, y tomar las muestras cuando el paciente tenga accesos de tos, sea de noche o de día"

La descripción que hace de la tos el profesor Trousseau merece rescatarse del olvido: "Un niño está en medio de sus juegos: algunos minutos antes que la crisis llegue, él se detiene; su alegría deja lugar a la tristeza; si se encontraba en compañía de sus camaradas, se aparta de ellos y busca evitarlos. Es entonces, permítanme, señores, esta expresión, es entonces cuando medita su crisis, la siente venir... Primero trata de hacer abortar la quinta; en lugar de respirar naturalmente, a pleno pulmón, como respiraba hasta ahora, retiene su respiración; parece comprender que el aire, llegando de lleno a su laringe, va a provocar esa tos fatigante, de la cual tiene triste experiencia... De inmediato verán al enfermo buscar a su alrededor un punto de apoyo: si es un niño al pecho, se precipita en lo brazos de su madre o de la nodriza... Pero, lo repito, cualquier cosa que haga nada impedirá, no podrá más que retardar la explosión ${ }^{8}$. "Medita su crisis": detengámonos, señores, y meditemos nuestra crisis: ¿en qué momento degeneró el lenguaje médico en la prosa aséptica, insípida y estereotipada de nuestros días? ¿Quién decretó que los médicos debemos "hablar en fome"?

Aislar a la Bordetella entretenía a los bacteriólogos, para desdén de los clínicos, a quienes les bastaba escuchar toser al niño para establecer un diagnóstico de certeza: "medicina basada en evidencias”. ¿De qué servía aislar la bacteria en una placa, identificarla, tipificarla y guardarla en colección? No existía un tratamiento que frenara esa tos incesante; las sustancias que inhibían in vitro el crecimiento de la pequeña malvada no eran tolerables por el cuerpo humano. Nació entonces la idea peregrina de eliminarla mediante una aireación rápida, quizás de la observación que el cultivo se favorecía con un ambiente de $\mathrm{CO}_{2}$ : si era así, un exceso de oxígeno la mataría. No existían cámaras hiperbáricas a comienzos del siglo XX, aunque Nobecourt empleaba ba- 
ños de aire comprimido, "por su acción antiespasmódica y de sobreoxigenación de la sangre". Buscando una alternativa más accesible a la mayoría, en 1917 Chalamel demostró y recomendó luego la eficacia de subir al enfermito a un automobile découverte, lo que hoy llamaríamos un deportivo convertible, y someterlo a un exceso de velocidad, con la consiguiente ventolera. El niño debía ubicarse de frente y la marcha "muy rápida" 10 . No se mire a huevo esta rapidez: el Renault 40 CV de 1911 tenía 7.536 cc en sus seis cilindros, con los que desarrollaba $145 \mathrm{~km} /$ hora; como era convertible, bastaba con bajarle la capota y el parabrisas abatible, poner al chiquillo adelante, acelerar y dejarlo despeinado y en apnea.

¿Cómo conseguir más aire y más velocidad? Simultáneamente, franceses y alemanes decidieron atacar a la pobrecita bacteria empleando la fuerza aérea. Walter Mater, un médico militar de Estrasburgo, se vio en 1927 enfrentado a un brote de coqueluche en un regimiento de aviación, circunstancia que le permitió disponer los medios necesarios para ensayar su método de curación en altura. Tuvo un relativo éxito y su técnica merece citarse en detalle: "Subir a una altura de 2.500 a 3.000 metros en diez a quince minutos, continuar máximo una hora a este nivel y luego hacer dos descensos pasajeros, en picada, de 500 metros cada uno; recuperar luego la altura, para descender finalmente al suelo a la misma velocidad de subida. El avión debe estar totalmente descubierto o al menos ampliamente comunicado al exterior". Había control médico permanente durante el vuelo, contraindicaciones excluyentes y reacciones mínimas ("a menudo los niños se duermen"). En los casos favorables, al día siguiente del vuelo había una exageración de las quintas, pero luego decrecían en número e intensidad, para desaparecer en algunos días, máximo dos semanas. Un $6 \%$ de los pacientes se agravaron; un 5\% tuvo efectos adversos serios; un 40 a $50 \%$ mostró mejoría y/o curación; no he encontrado cifras más rigurosas. Por su parte, el médico berlinés Kettner, utilizando aviones alemanes cerrados, obtuvo un $10 \%$ de éxito; sus colegas argumentaron que no era un tratamiento etiológico sino psicológico, en lo que no andaban descaminados, y la conclusión final fue la condenación del método por inútil $1^{11,12}$.

Hace casi treinta años, en el curso de las Cuartas Jornadas Anuales de la Sociedad Chilena de Pediatría, a orillas del Calle-Calle, Antonio Banfi resumió el tratamiento de la coqueluche en cinco puntos: general, antimicrobiano, inmunización pasiva, complicaciones y avances ${ }^{13}$. Resulta desalentadora la comparación con el tratamiento actual, pues uno y otro no difieren en mucho. En 1916, empieza Banfi, en el Seminario Médico Alemán se decía que "recientemente se ha hablado de la eficacia del empleo de suero del convaleciente de coqueluche y de una preparación etérea con desgarro de los enfermos, propuesta por Krauss"; una década después, en su texto clásico de pediatría señalaba Finkelstein que "las inyecciones de éter me parecen ineficaces, pero con los preparados de quinina creo haber observa- do alivio de los accesos y una menor duración de la enfermedad". Y, siguiendo con los tratamientos históricos, menciona, aparte del ya comentado vuelo en avión, la luz ultravioleta, la vacunación con Bordetella viva, el extracto de vesícula biliar de buey, la "medicina de hierbas chinas" y la hemoterapia. A ellas habría que agregar las inhalaciones de bencina, de trementina, de gases extraídos de las cámaras de limpieza del gas de alumbrado, de ácido fénico, de morfina, de agua de laurel-cerezo, de tintura de opio, de cloroformo y distintos bromuros, todas ellas en la etapa catarral, para abortar el paso al período espasmódico. Y, para sedar la tos, el beleño, el cáñamo indio, el opio, la belladona, el cornezuelo de centeno y el hidrato de cloral ${ }^{2}$.

Dejando de lado lo pintoresco, entra luego Banfi en el análisis del tratamiento en 1974, discutiendo la acción sobre la tos del fenobarbital, el meprobamato, el diazepam y la tioridazina, todos medicamentos sin acción concluyente demostrada entonces ni ahora. En cuanto a los antibióticos, eritromicina era la droga de elección... Sobre la inmunización pasiva, comienza con el estudio de Bradford en 1935, que merece algún comentario. Bradford hizo una extensiva revisión de la literatura sobre el empleo profiláctico y terapéutico, tanto de sangre como de suero de convalecientes, cotejándola con su propia experiencia, concluyendo que si bien habría una ligera ventaja en el uso precoz, ni en el período catarral ni el paroxístico tenían una utilidad significativa o concluyente $^{14}$.

Después de esto, vinieron los trabajos con inmunoglobulina específica anti-pertussis, producto que mostró resultados iniciales convincentes en estudios no controlados, hasta que Balagtas, con un protocolo bien diseñado, echó un balde de agua fría a las esperanzas depositadas en el producto ${ }^{15}$. Nuestra propia experiencia, mostrada por Banfi en esas Jornadas, fue decepcionante y nunca se publicó, ya que no hubo diferencia significativa entre los 104 niños tratados y el grupo control. Y peor todavía nos fue con el empleo de "plasma añejo", que utilizamos con un oscuro y discutible fundamento.

Estos tratamientos pretendían, sin saberlo, neutralizar las toxinas del bacilo de la coqueluche, aunque éstas aun no estaban claramente definidas. Bordet y Gengou sostenían que su bacteria no producía exotoxinas, pero sí una endotoxina, que extraían laboriosamente y con la cual mataban conejos en 18 horas. Con los años y los avances de la ciencia, se fueron precisando otras acciones tóxicas, atribuibles a distintas toxinas o "factores", hasta llegar al trabajo clásico y revolucionario a la vez de Margaret Pittman en $1984^{16}$, que presentaba a la coqueluche como una toxemia, dando validez definitiva al "pertusinógeno", la toxina causante de los muchos efectos atribuidos a distintos elementos de la Bordetella. Esta imprecisión de tantos años en cuanto a las toxinas y mecanismos patógenos de la bacteria fue lo que entrabó siempre el desarrollo de una adecuada vacuna. Bordet y Gengou buscaban un toxoide... y no lo encontraron. 
Una completa reseña de Tanner Hawlett ubica los primeros ensayos de vacunación anti-pertussis, datan de comienzos de siglo veinte. En 1914, Hess vacunó a 244 niños con una vacuna celular entera y muerta, de los cuales enfermaron 20 , en tanto que de 80 controles no vacunados, enfermaron 59. Casi simultáneamente, entre 1915 y 1917, Luttinger vacunó a una cifra similar, enfermando 23 de los 239 niños vacunados, estimando una protección gruesa del $90 \%$. Probada así la vacuna, el primer estudio de campo propiamente tal se realizó en las islas Feroe por Madsen, aprovechando una gran epidemia que se inició en 1923, la cual le permitió inmunizar cerca de 2.000 individuos, con resultados bien discretos: en un distrito el $20 \%$ de los vacunados escapó a la enfermedad, en tanto que de 108 no vacunados sólo se salvaron 2, lo que daría apenas un $20 \%$ de protección. Sin embargo, se logró reducir apreciablemente la letalidad de la enfermedad, pues fallecieron 5 de 2.094 vacunados, versus 18 de 627 no vacunados, lo cual es estadísticamente significativo y le dio un espaldarazo al método ${ }^{17}$.

La vacunación como tratamiento es más antigua aún y la inició Freeman ${ }^{18}$ en 1909. Más temerarios, Nicolle y Conor $^{19}$ se atrevieron a usar una vacuna viva a guisa de tratamiento en una epidemia en Túnez en 1913, para lo cual hicieron cultivos en agar sangre con papa, los emulsionaron y lavaron varias veces, para llegar a una suspensión salina de 400 millones de bacilos por gota. Esta vacuna se inyectó subcutáneamente cada dos o tres días, tantas veces como fuera necesario, en dosis de 1 a 5 gotas, con lo cual declararon haber curado al $78 \%$ de los casos en 3 a 12 días. Una infinita discusión se estableció entonces sobre la efectividad terapéutica de las vacunas muertas, ya sea con $H$. pertussis sólo o combinado con $H$. influenzae, desde la categórica declaración de von Sholly ${ }^{20}$, en el sentido que iguales éxitos podían obtenerse empleando "agua coloreada con leche", hasta la ponderada conclusión de Luttinger ${ }^{21}$, que hablaba de una reducción del período de estado de 40 días en los no vacunados, a 25 en los vacunados, y el serio trabajo de Herman y Bell12 ya en 1924, con un grupo de 300 pacientes tratados con vacuna, en los que en $25 \%$ la mejoría fue tan marcada "que no hay duda de su efecto específico".

La vacunación comenzó a discutirse en Chile en los años 30's, cuando la tasa de morbilidad era de 150 por 100.000 , subiendo a 340 en los períodos epidémicos, con una letalidad que llegaba al $26 \%{ }^{23}$. En una reunión de anatomía patológica del Hospital Arriarán, del 23 de junio de $1931^{24}$, vemos que existía todo un Servicio de Coqueluche, enfermedad que daba el papirotazo final a los tuberculosos, tal cual como leemos en el lenguaje florido de la época, refiriéndose al prescolar de 5 años Alfonso N..: "La coqueluche apagó su alegría y la tuberculosis extinguió su vida". Luego de una gran polémica entre las ventajas de usar la vacuna preventiva o la curativa, el Instituto Bacteriológico se abocó al desarrollo de esta última.

A comienzos de los años 40's tenemos el ensayo de Emilio Prado, Conrado Ristori y la memorista María Villalobos ${ }^{25}$, con 1.220 vacunaciones completas con una vacuna mixta muy recargada: $30 \mathrm{Lf}$ de toxoide diftérico y 40 mil millones de Haemophilus pertussis, que así se llamaba entonces. Hoy sabemos que, inserto el género en la tercera superfamilia, está más cerca de Acinetobacter que de Haemophilus. La morbilidad comparada dio $0,32 \%$ para los vacunados, contra $8,83 \%$ en los no vacunados. Fue un año excepcionalmente epidémico, que se prestó para el ensayo. La eficacia estimada fue del $96 \%$. Pese al buen resultado, razones técnicas postergaron en 8 años el inicio de la vacunación mixta en Chile, que comenzó en abril de 1951, con 56.326 inmunizaciones completas $^{26}$.

Las reacciones adversas de la vacuna pertussis constituyen uno de los grandes mitos de la medicina moderna. Revisando los trabajos que lo originaron, vemos registradas muertes súbitas ocurridas meses post-vacunación, en tanto que un estudio contemporáneo con vacunas acelulares descarta tres de ellas elegantemente, porque se produjeron después de las 72 horas. Una reciente editorial del JAMA ${ }^{27}$ comenta los tres últimos estudios realizados al respecto y dice que, en cerca de 230.000 niños y 713.000 inmunizaciones, no se encontró evidencias de una relación causal entre la vacuna y un permanente daño neurológico. Personalmente, creo que este mito ha sido beneficioso, pues ha permitido desarrollar mejores vacunas, no en cuanto a las menores reacciones adversas, sino a que son mejores y más específicos antígenos.

La variación antigénica fue puesta en órbita por Preston $^{28,29}$ en Inglaterra, en los años 60, al conceder una desusada importancia a aglutinógenos que nadie ha podido individualizar correctamente y que parecen corresponder a organelos de adherencia. En todo caso, los fabricantes de vacunas enteras se han preocupado siempre de incluir cepas que posean todos estos antígenos, que son de Anderson, quién los describió una década antes ${ }^{30}$ y no de Preston, quien sólo los publicitó.

A la Bordetella todos los esfuerzos médicos, desde Bordet acá, le importan un cuesco, y la coqueluche se ha convertido, legítimamente, en la última de las pestes infantiles.

\section{Bibliografía}

1.- Laín Entralgo P. Historia de la Medicina. Salvat Editores, S.A., Barcelona 1977, p: 489.

2.- Eulenburg A. Diccionario Enciclopédico de Medicina y Cirugía Prácticas. Agustin Jubera, Editor, Madrid 1887; V: 361-72.

3.- Bordet J, Gengou O. Le microbe de coqueluche. Ann Inst Pasteur 1906; 20: 731-

4.- Tanner Hewlett, R. Whooping Cough. Aetiology. In: A System of Bacteriology in relation to Medicine, His Majesty's Stationery Office, London 1930; 2: 395-6.

5.- Chievitz I, Meyer A H. Le diagnostic bactériologique de la coqueluche. Ann Inst Pasteur 1916; 30: 503-9. 
6.- Millikin D. Bordet, Jules Jean Baptiste Vincent. Collier's Encyclopedie. Crowell Collier \& McMillan, USA 1967; 4: 393.

7.- Larousse Pocket Español Francés. Ediciones Larousse S.A. de C.V., México D.F. 1994.

8.- Trousseau A. Clinique Médicale de l'Hotel Dieu de Paris. Deuxiéme éd. J-B. Baillière et fils, Libraires de l'Academie Impériale de Médecine, Paris 1865; II: 413-33.

9.- Marie J. La coqueluche. En: Maladies infectieuses, Encyclopédie Médico-Chirurgicale. 1ere éd. 18 Rue Séguier, Paris 1935; 8017-8.

10.- E.M.C. Sur le méthode de Strabourg dans le traitement de la coqueluche. Addendum à Maladies Infectieuses, Encyclopédie Médico-Chirurgicale. 2e. éd, 18 Rue Séguier, Paris 1947; 8017 C: 11 a.

11.- Levent R. Le méthode de Strasbourg dans le traitement de la coqueluche. Gaz Hop 1947; 8: 121-2.

12.- Evrard E, Simar A. Un cas grave de coqueluche traité par le vol en avion. Bruxelles Méd 1947; 12: 650-4.

13.- Banfi A. Coqueluche: tratamiento y complicaciones. Rev Chil Pediat 1975; 46: 287-90.

14.- Bradford W L. Use of convalescent blood in whooping cough. With a review of the literature. Amer J Dis Child 1935; 50: 918-25.

15.- Balagtas R, Nelson K, Levion S, Gottof S. Treatment of pertussis with pertussis immunoglobulin. Pediatrics 1971; 79: 203-8.

16.- Pittman M. The concept of pertussis as a toxinmediated disease. Pediatr Infect Dis 1984; 3: 476-86.

17.- Madsen,T. Pertussis in Feroe Islands. Boston Med Surg J 1925; 192: 50
18.- Freeman, J. On the treatment of whooping cough with pertussis vaccine. Brit Med J 1909; ii: 1064.

19.- Nicolle C, Connor A. CR Résultats de la vaccinoprophylaxie de la coqueluche. Acad Sci Paris 1913; 156: 1849.

20.- Von Sholly, Bean J, Smith L. Pertussis vaccine. JAMA 1917; 68: 1451.

21.- Luttinger P. Pertussis immunization. NY Med J 1915; 101: 1043.

22.- Herrman C, Bell T. Treatment of whooping cough by means of a pertussis vaccine. Arch Pediatr 1924; 41: 13-26.

23.- Ristori C. Actas. II Jornadas Chilenas Salubridad, U. Chile, 1952.

24.- Reuniones anatomo-clínicas. Hospital Arriarán. Rev Chil Pediatr 1931; 2: 566.

25.- Prado E, Ristori C, Villalobos M. Vacunación mixta antipertussis diftérica en dos dosis. Rev Chil Hig Med Prev 1944; 6: 307.

26.- Kirschbaum A. Difteria, pertussis, tétano. En: Resúmenes del Taller de DPT, Mayo 1988, I. Salud Pública Chile, p. 2.

27.- Cherry J D. Editorial. Pertussis vaccine encephalopathy: it is time to recognize it as the myty that it is. JAMA 1990; 263 (12): 1679-80.

28.- Preston N W. Effectiveness of Pertussis vaccines. Brit Med J 1965; 5452: 11-3.

29.- Preston N W. Type specific immunity against whooping cough. Br Med J 1963; 5359: 724-6.

30.- Andersen E K. Serological studies on H. pertussis, H. parapertussis and $\mathrm{H}$. bronchisepticus. Acta Pathol Microbiol Scand 1953; 33 (2): 202-24. 